\title{
Pastejo rotacionado para criação de bovinos de corte no estado do Tocantins
}

A importância do estudo de plantas forrageiras tornou-se fundamental para se obter uma criação de bovinos de corte com alta qualidade em um sistema de pastejo rotacionado. Mas antes de iniciar o projeto do sistema de produção na propriedade, devemos realizar um diagnóstico completo do local e das condições reais do produtor. O trabalho foi desenvolvido com base em uma pesquisa bibliográfica de caráter qualitativo, descritivo e exploratório, utilizando artigos científicos, livros e revistas a respeito do tema estudado. Pelos resultados obtidos através de vários experimentos, foram comprovados que, dentre todos os aspectos, o mais analisado é o bem-estar animal. Neste contexto, não poderia haver investimento em um projeto de pastejo rotacionado se esse fator não for levado em consideração. Portanto, o rendimento da produção só terá efeito se o animal for bem tratado, e dessa forma será recíproco ao criador, pois o animal se encontrará em condições favoráveis para se desenvolver.

Palavras-chave: Bovino; Pastejo; Cerrado; Tocantins.

\section{Rotated grazing for breeding beef cattle in the state of Tocantins}

The importance of the study of forage plants has become fundamental to obtain high quality cattle breeding in a rotational grazing system. But before starting the project of the production system in the property, we must make a complete diagnosis of the location and real conditions of the producer. The paper was developed based on qualitative, descriptive and exploratory bibliographical research, using scientific articles, books and journals about the subject studied. From the results obtained through several experiments, it has been proven that, among all aspects, the most analyzed is animal welfare. In this context, there could be no investment in a rotational grazing project if this factor is not considered. Therefore, yield of production will only take effect if the animal is well treated, and thus will be reciprocal to the breeder, since the animal will be in favorable conditions to develop.

Keywords: Bovine; Rotate; Thick; Tocantins.

\section{Topic: Nutrição Animal}

Reviewed anonymously in the process of blind peer.
Received: 15/07/2017

Approved: 16/10/2017
Andreia Jorge Lomazzi

Faculdade Guaraí, Brasil

http://lattes.cnpq.br/6658135610224225

andreialomazzi@hotmail.com

Rosana Xavier Nunes

Faculdade Guaraí, Brasil

http://lattes.cnpq.br/5528574410177462

rosana.xn@hotmail.com

Weverson Marlus Menezes da Silva Pinto Faculdade Guaraí, Brasil

http://lattes.cnpq.br/4131786811504704

weversonmarlus@gmail.com

\author{
Gian Carlos Piton \\ Faculdade Guaraí, Brasil \\ http://lattes.cnpq.br/1875685350800192 \\ giancpiton@hotmail.com \\ Carla Regina Rocha Guimarães \\ Faculdade Guaraí, Brasil \\ http://lattes.cnpq.br/7142063757833875 \\ carla.guimaraes@faculdadeguarai.com.br \\ Fernando Barnabé Cerqueira \\ Faculdade Guaraí, Brasil \\ http://lattes.cnpq.br/1604638349819259 \\ fernando1.981@hotmail.com
}




\section{INTRODUÇÃO}

A importância do estudo de plantas forrageiras tornou-se fundamental para se obter uma criação de bovinos de corte com alta qualidade em um sistema de pastejo rotacionado, mas antes de iniciar o projeto do sistema de produção na propriedade devemos realizar um diagnóstico completo do local e das condições reais do produtor.

A melhor forma de analisar o pastejo rotacionado é maximizar a produção animal sem afetar o desenvolvimento das plantas forrageiras, constituindo uma combinação ideal solo - planta - animal ambiente, atingindo por fim melhores índices de produtividade. Durante a implantação deste sistema, alguns fatores devem ser analisados como a capacidade de suporte da pastagem, categoria animal, tamanho do rebanho, espécie forrageira, tempo de ocupação de piquetes, período de descanso, número e dimensionamento dos piquetes, de modo alcançar a eficiência deste sistema (PEDREIRA, 2005).

De acordo com Silva (1995), o manejo das pastagens assume um papel de fundamental importância para a produtividade animal, uma vez que é somente por meio do conhecimento, da manipulação e alocação correta dos fatores de produção, do solo - clima - planta forrageira - animal se poderá obter uma produtividade e rentabilidade favorável dentro de qualquer sistema de produção.

Como a história da pecuária no Estado do Tocantins teve início por volta da década de 50 e 60, tendo essa origem ligada ao Estado de Goiás, sabe-se que os primeiros municípios onde se instalou esta atividade foram: Arapoema, Araguaína, Colinas do Tocantins, Xambioá, Araguacema, Paraíso do Tocantins e Gurupi (ARAÚJO, 2013). Boa parte da área de pastagem tocantinense não obteve mudança ao longo do tempo e é explorada de forma extensiva com áreas formadas a cerca de 30 anos onde durante este período não se obteve um processo de recuperação e por consequência encontra-se com áreas degradadas (VALLE, 2000).

Atualmente $80 \%$ das propriedades rurais estão dedicadas à pecuária no Estado, onde estas áreas destinadas ao pastejo acabam por suportar somente um ou dois animais por ha, sendo este um dos fatores que ocasiona a redução da rentabilidade dos pecuaristas provocando de certa forma uma "fuga" para outras atividades como, por exemplo, a agricultura. Outro fator existente é o fato de que muitas terras que se tornaram degradadas e até mesmo improdutivas, chegando a ocasionar a desistência e o abandono desta atividade por parte dos pecuaristas.

Desse modo, realizar o pastejo rotacionado levaria os produtores e criadores a permanecerem no campo, visando assim promover o bem-estar animal, na busca de se obter um melhor resultado econômico, aumentando a eficiência do sistema de criação e melhor qualidade do produto, onde finalmente atenderá de forma eficaz e satisfatória as expectativas do mercado consumidor. Neste contexto, o presente trabalho teve como objetivo levar informações sobre a adoção do sistema de pastejo rotacionado para o Estado do Tocantins, com técnicas de manejo fundamentais para quem pretende aumentar sua capacidade de suporte e melhorar o desempenho de sua produção. 


\section{METODOLOGIA}

O trabalho foi desenvolvido com base em uma pesquisa bibliográfica de caráter descritivo, exploratório e qualitativo. Foi utilizado método empírico, que por sua vez usou como apresentação dos propósitos a pesquisa, a junção e categorização dos fatos, além do levantamento de dados e objetos com o intuito de levantar projetos para explicá-lo.

Para o levantamento de artigos, utilizou-se as palavras-chave "bovino", "pastejo rotacionado"; "cerrado", "criação de bovinos", "Tocantins" publicados em plataformas de periódicos Sientific Electronic Library Online (SciELO), Google Acadêmico, Coordenação de Aperfeiçoamento de Pessoal de Nível Superior (CAPES) e LILACS (Literatura Latino-americana em Ciências da Saúde).

\section{DISCUSSÃO TEÓRICA}

\section{Sistemas de produção de bovinos de corte no Estado do Tocantins}

O Estado do Tocantins é uma região voltada a atividades rurais, onde a pecuária de corte vem demonstrando um índice de crescimento expressivo nos últimos anos, com um processo de transformação tecnológica acelerada. Como as pastagens cultivadas no Tocantins, abordam uma importância muito grande para o Estado, que merece uma atenção mais relevante às recomendações técnicas e de suporte adequadas para sua sustentabilidade, pois cerca de $70 \%$ dos principais recursos de pastagens estão em declínio de produtividade, por consequência do alto processo de degradação ao meio ambiente que se encontram (ARAÚJO, 2013).

O Estado possui uma área coberta de pastagem com cerca de $40 \%$, ou seja, se estas pastagens não forem manejadas de forma adequada, o sistema de produção em que elas se baseiam não será mantido com o passar do tempo e, como consequência o Estado terá altos prejuízos de forma econômica, ambiental e social. Podemos destacar diversos fatores como causa deste quadro de declínio, porém, se revestem com maior importância os seguintes: inadequada implantação de pastagens, inadequada correção e adubação do solo e manejo inadequado das pastagens (ARAÚJO, 2013).

Como não são raros os acontecimentos em que, mesmo avisados, os pecuaristas ameaçam o seu plantio em áreas não recomendadas, acaba-se por gerar a perda da capacidade produtiva no decorrer dos anos. Um plantio inadequado provocou recentemente a síndrome da morte do capim marandu, na região pré-Amazônica, sendo causada pelo excesso de umidade no solo, em razão deste acontecimento, milhares de hectares foram afetados ocasionando assim grandes prejuízos econômicos e ambientais para esta região (VALENTIM et al., 2002).

O Tocantins tem crescido bastante no ramo do agropecuário, sua área de criação de bovino de corte é considerada como a maior tradição no país. O rebanho bovino tocantinense passou de 4,2 milhões de cabeças em outubro de 1988, para 8,2 milhões em outubro de 2013, este crescimento foi confirmado em 93\%, como um dos maiores do Brasil (ARAÚJO, 2013). Dentre os vários tipos de criação de bovinos a pasto conhecidos nesta região, existem três tipos de sistemas que mais prevalecem na pecuária brasileira e 
tocantinense. As categorias foram separadas e consideradas como "ponto de corte" da seguinte forma (CEZAR et al., 2005): "sistema extensivo - onde predomina o regime exclusivo de pastagem; Sistema semiintensivo - onde se é utilizado à pastagem mais suplementação em pasto; e Sistema intensivo - que mistura a pastagem mais a suplementação juntamente com o confinamento".

O sistema extensivo é caracterizado pelo pastejo contínuo geralmente em pastagens nativas, é também o sistema mais utilizado principalmente quando se fala em bovinos de corte. Possui em sua maioria uma grande quantidade de terra disponível, e é considerada como a principal fonte de alimentação, feita neste caso com a pastagem natural, por isso dependendo dos fatores externos como clima, condições topográficas e até mesmo a própria fertilidade do solo a produção das pastagens pode variar entre média e baixa, pois normalmente não é feito adubação ou mesmo a correção do solo, afetando a produção das forragens, fazendo com que as mesmas não se mantenham nas épocas das secas, deixando assim o animal a mercê quanto ao consumo do alimento. Além de conter uma baixa densidade de animais por área, com os rebanhos em grandes superfícies, ocasiona dessa forma a lotação no pastejo e a degradação do próprio solo pelo pisoteio dos animais (BARRETO et al., 1994).

No sistema semi-intensivo apresenta um tipo de vegetação também de forma nativa, às vezes melhorada misturando-a com a suplementação, minerais acrescidos de suplementos proteicos e energéticos aos animais. Onde se tem o objetivo de alcançar um ciclo mais curto e dessa forma introduzir a suplementação em todas as fases, dentre elas o aleitamento, a recria e a engorda, que compõem as etapas de crescimento do animal (CEZAR et al., 2005).

Já no sistema intensivo, há certas exigências quanto ao manejo dos animais, pois mantém a prática do confinamento principalmente em terminação de machos, período que antecede o abate. Difere também dos anteriores, pois já passam a oferecer aos animais a pastagem de forma cultivada, ou seja, os criadores se associam mais precisamente a plantas seletivas, como por exemplo, as espécies dos gêneros Brachiaria e Panicum, que facilitam no manejo e são mais aceitáveis pelos animais. O fato de se utilizar o confinamento é importante, pois se tem a preocupação de reduzir gastos na alimentação, pois se utiliza dietas com relação ao volumoso. Além de o animal obter um tempo mais curto para atingir o peso adequado (CEZAR et al., 2005).

No Tocantins, o que mais predomina é o sistema de pastejo extensivo, onde ocorre em sua maioria, nas grandes propriedades. Entretanto há alguns fatores que podem prejudicar a produção em si, fatores como: gramíneas, solo, compactação, degradação, a falta ou o mau manejo, e as próprias queimadas que podem ocasionar problemas futuros aos criadores e consequentemente ao rendimento da produção (NOGUEIRA, 2011).

Como a pecuária de corte que é tradição no Estado do Tocantins utiliza principalmente o sistema de criação extensivo, onde os pecuaristas tocantinenses criam os animais soltos em áreas e extensões grandes e sem promover grandes cuidados, acaba gerando fatores que implicam a ter uma baixa produtividade. Sendo que o produto final, neste caso a carne recebe um aspecto mais duro devido à musculatura mais rígida dos animais ao subir e descer morros em busca de alimento, mais vale ressaltar que a musculatura mais rígida 
não gera uma qualidade ruim para o produto, isso depende de outros fatores como o tipo de alimento consumido pelo animal e o manejo durante seu desenvolvimento (NOGUEIRA, 2011).

\section{Sistemas de pastejo}

É o sistema onde o período de uso e de descanso da pastagem é manipulado dentro do período de crescimento da planta. A combinação definida de integrar o animal, a planta, o solo, o ambiente e o método de pastejo, no qual o sistema é manejado para que o pecuarista possa atingir os objetivos esperados. Os métodos de pastejo têm influências desde a quantidade de forragem consumida diariamente pelo animal até o modo como a forrageira é pastejada. Respeitando os limites de recuperação da planta forrageira e a produção de massa verde após o último período de pastejo, onde a nova massa verde disponível terá uma influência direta no desenvolvimento do animal e no seu ganho de peso (MIRANDA, 2007). Antes de citar os tipos de pastejo com os animais é válido ressaltar três fatores fundamentais que fazem parte de qualquer tipo de sistema de pastejo (COSTA, 2007):

a) Dias de ocupação: período onde os animais permanecem pastejando em uma determinada área;

b) Dias de descanso: período onde são estipulados dois pastejo subsequentes, no qual se alterna o pastejo entre ambas para que a pastagem fique em repouso para que possa rebrotar. Varia desde pastejo contínuo, sem dias de descanso até sistemas com amplos períodos de descanso, em que o período de ocupação fica reduzido há cerca de dois dias ou menos, como ocorre no pastejo rotacionado;

c) Pressão de pastejo: relação entre número de animais que estão em pastejo e a quantidade de forragem disponível para sua alimentação. Este tópico geralmente é confundido com a taxa de lotação, porém a diferença está relacionada à carga animal e a área, levando em consideração a disponibilidade de forragem no local. Independentemente do método de pastejo contínuo ou rotacionado, a pressão é um fator determinante para o sucesso ou insucesso na realização do manejo.

A pressão de pastejo deve ser no nível que permitam a seleção da forragem ingerida, assegurando níveis aceitáveis de sobrevivência animal e rendimentos de acordo com as circunstâncias socioeconômicas. Durante o manejo da pastagem deve-se procurar estabilizar a pressão de pastejo e/ou a disponibilidade de forragem em níveis, que mesmo não apresentando um nível máximo de ganho por animal, venha a proporcionar níveis máximos de ganho por área, que por fim gera uma amplitude considerada ótima, pois através desta forma a pastagem chega a representar seu potencial produtivo, conciliando então alta produção de forragem com alto valor nutritivo (COSTA, 2007).

A classificação para os sistemas de pastejo é amplamente complexa, especificando este tópico para mesorregião ocidental do Estado do Tocantins as técnicas de manejo são consideradas, simplificadas. Os sistemas de pastejo se classificam em dois: pastejo contínuo e pastejo rotacionado. Onde o pastejo rotacionado se subdivide: em diferido, "com descanso" e combinado. A escolha do sistema de pastejo pode ser baseada no conhecimento da fisiologia das plantas que serão utilizadas, vinculadas ao tipo de animal e ao nível de produção que se deseja obter (COSTA, 2007).

A região tocantinense possui alguns fatores que normalmente interferem na adoção do método de pastejo, presente também em outras regiões, só que em maior nível, são os seguintes: localização e 
disponibilidade de área, topografia do solo, recursos financeiros para construir cercas, compra de adubo, plantio de forrageiras adequadas para o tipo de solo e manutenção do sistema escolhido (COSTA, 2007).

O método escolhido deve ser o mais lucrativo e nenhum deles servirá unicamente para todas as fazendas. Então de maneira primordial devemos entender que cada propriedade apresenta características que a torna diferente das demais.

\section{Pastejo contínuo}

O pastejo contínuo é o mais utilizado na região tocantinense e possui como característica a permanência contínua e ilimitada do rebanho em uma área durante semanas, meses, uma estação ou anos de pastejo, podendo ocorrer esta permanência em pastagens com ciclos temporários ou anuais. É utilizado normalmente em pastagens nativo-naturais onde se obtêm um resultado baixo nas taxas de produção. Destaca-se que mesmo sendo um sistema de pastejo contínuo não se admite a total ausência de cercas divisórias, pois os animais devem ser separados em categorias de idade, sexo, espécie e outros. Diversas práticas podem ser adotadas para aumentar a eficiência deste tipo de pastejo e da sua produção. As práticas mais adequadas para este desenvolvimento são (JUNIOR, 2001): a) A divisão do número adequado de animais e separação das diferentes categorias de acordo com a capacidade de produção da pastagem; b) Implantação de cercas e reajuste na distribuição de água, sal e sombra; c) Realizar práticas de Limpeza de pastagens; d) Diferimento de áreas com propósito de reduzir os períodos críticos; e) Suplementação mediante forragem conservada e/ou utilização de pastagens suplementares.

Entretanto, há vantagens e práticas de melhoramentos para se alcançar um bom desenvolvimento de manejo existem, como: Seletividade de áreas e espécies de forrageiras; Irregularidades durante a distribuição de excrementos; Aumento de espécies invasoras quando o pastejo é mantido com alta lotação, mesmo durante os períodos críticos.

A variação da carga animal neste tipo de sistema é recomendada, referente à estacionalidade na produção de pastagem durante o ano, adotando uma lotação para o período chuvoso e outra, menor, para o período seco. Quando o pecuarista adota uma lotação fixa, deve-se usar como base de lotação, a capacidade de suporte no período seco. Em geral este tipo de sistema apresenta uma baixa produtividade e uma rentabilidade inferior quando comparado com o sistema rotacionado (COSTA, 2007).

\section{Pastejo Rotacional}

É um sistema de pastejo onde a área de pastagem é dividida em piquetes e estes são utilizados por certo período, chamado de período de ocupação, ao término deste, o piquete entrará em período de descanso e será realizada a transferência dos animais para o próximo piquete (COSTA, 2007). Este sistema inclui a limitação do pastejo dos animais em pelo menos duas áreas de pastejo alternado ou mais divisões para que eles possam aproveitar a produção de forragens. Já em relação ao período de pastejo, é variável, podendo ser de 30, 21, 14 e 7 dias, ou também pelo crescimento das plantas do próximo piquete a ser pastejado e do que está sendo utilizado (MORAIS, 1995). Vários sistemas de manejo rotacionado, surgiram 
para subdividir e utilizar as pastagens, isto, para aplicar respostas das plantas forrageiras utilizadas e pelas diferentes classes animais (REIS et al., 1997). De acordo com Melado (2003), pode-se classificar os diferentes métodos de pastejo rotacionado em: Lotação Rotacional (Convencional); pastejo em faixas; pastejo primeiro e último (Rotacional com dois grupos); Creep "grazing"; Creep "grazing” avançado; pastejo diferido; e Pastejo Limite.

\section{Lotação Rotacional}

Nesse método, as áreas fracionadas em dois ou mais piquetes, favorece descanso periódico as plantas forrageiras, onde a duração depende do número de divisões e extensão do período de ocupação de cada piquete. A carga animal ou a pressão de pastejo pode ser fixa ou variável (MIRANDA, 2007). Outra característica deste método é a mudança dos animais de forma periódica e frequente de um piquete para outro de maneira contínua, retornando ao primeiro após finalizar o ciclo (MENDES, 1999).

O pastejo rotacionado tem sido recomendado e baseado na hipótese de que as plantas precisam de um período de descanso, a fim de se recuperar as desfolhações, concedendo a reposição das folhas e o restabelecimento dos níveis de reserva (MIRANDA, 2007), exigindo um grande investimento em instalações especialmente bebedouros e cercas caracterizando-se por restringir a seletividade animal. Já o pastejo e a distribuição de excrementos são analisados de maneira semelhante, a forragem é tratada em um estado mais tenro e com melhor valor nutritivo. Quando o sistema de pastejo rotacionado é executado corretamente, complica o estabelecimento de plantas invasoras e facilita o aproveitamento do excesso de forragem produzida na região pela estação chuvosa (MELADO, 2003).

A quantidade de subdivisões deve ser minuciosamente calculada para que a aplicação investida não se torne antieconômica, ou venha proporcionar um retorno menor do que o investido com fertilizantes para recuperação ou renovação de pastagens. Melado (2003) observam que o sistema de pastejo rotacionado apresenta diversas variações em função da quantidade de subdivisões, período de ocupação e descanso utilizados, onde os quais variam de acordo com a área disponível, clima da região, fertilidade do solo, tipo de exploração, características morfológicas e fisiológicas das plantas forrageiras e outros.

A lotação rotacionada é considerada como método de pastejo rotacionado convencional, onde o grupo de animais é deslocado de um piquete para outro à medida que a altura da vegetação desejada é atingida, a disponibilidade de forragem é alta no início do pastejo de cada piquete e baixa no fim do período de ocupação (MELADO, 2003).

\section{Pastejo em faixas}

O método do pastejo em faixas é também denominado de pastejo racionado, é descrito pela entrada dos animais a uma área limitada e ainda não pastejada. Neste método o manejo é coordenado com o suporte de duas cercas elétricas de fácil remoção, de modo que a cerca posterior impeça o retorno dos animais as áreas pastejadas anteriormente (MELADO, 2003). O tamanho da área de cada faixa é minuciosamente calculado para oferecer aos animais a quantia de volumosos que precisam por dia. Esta exploração é mais 
recomendada aos animais leiteiros que possuem uma produção elevada, devendo-se também utilizar forrageiras com alto valor nutritivo (TAYAROL, 1997).

\section{Sistema de Pastejo primeiro e último}

Dentre as circunstâncias de pastejo, este método é mais conhecido na região tocantinense como líderes e seguidores, é uma conduta interessante, pois disponibiliza aos animais de diferentes portes, a apresentarem diferenças eficazes de resposta a forragem de alta qualidade. De acordo com MELADO (2003), os animais que melhor correspondem às condições de qualidade pastejam à frente, formando assim o primeiro grupo, ou como é mais bem conhecido "grupo dos líderes".

Esta disponibilidade inicial de forragem consente um pastejo seletivo e uma melhor ingestão de nutriente, o que resulta em maior produção animal. Os animais líderes pastejam por dois ou três dias, consumindo assim a forragem de melhor qualidade e após seguem para o próximo piquete para conceder o lugar ao segundo grupo de animais, também denominados de seguidores, que são beneficiados com o que sobrou (MARASHIN, 1994). É interessante a utilização deste método, quando se possui categorias diferentes de animais e necessita-se oferecer a elas uma dieta apropriada às suas exigências exclusivas dentro de uma mesma área de lotação rotativa (MARASHIN, 1994).

\section{Creep grazing}

Esse método possibilita que os bezerros jovens atravessem uma pequena abertura de cerca para entrada em um piquete que comporta uma forragem de melhor qualidade do que aquele em que suas mães são mantidas (COSTA et al., 1997). O sistema 'Creep Grazing' não necessita de gastos elevados, destacando somente o requerimento da formação da área com forrageiras de alta qualidade, para os animais mais jovens e as despesas adicionais para cercá-la, como regra o ganho/bezerro se eleva e a condição dos animais é melhorada (MELADO, 2003).

\section{Creep grazing 'avançado'}

Esse método é semelhante ao anterior, onde somente um número reduzido de animais ou categorias tem por meio de um instrumento adequado a permissão ao piquete seguinte, sem que os demais animais não selecionados tenham a mesma passagem preferencial. Isto proporciona um pastejo seletivo sem uma alta condição de competição (MELADO, 2003).

\section{Pastejo diferido}

Esse método de pastejo baseia-se na vedação de uma determinada área de pastagem, durante o seu período de crescimento com o objetivo de revigorar a pastagem e possibilitar o acúmulo de forragem nesta área do campo, para que ele seja utilizado no período de inverno. Este método é considerado por alguns autores como opção de pastejo rotacionado, é também denominado como diferido, quando o piquete é paralisado para descanso sem lotação de animais por um determinado período. Os motivos mais comuns 
para este acontecimento é a ressemeadura de uma ou mais espécies que completam esta pastagem, que será utilizada como reserva de alimento para o período de estiagem (período de seca), como propósito de revigorar as plantas forrageiras ou até como estratégia para auxiliar a modificação botânica (MELADO, 2003).

Além disso, esse sistema reconhece que ocorrem períodos críticos na fenologia das plantas desejadas na pastagem e cita como exemplo o florescimento e a produção de semente. Gerando a finalidade de permitir que as espécies mais palatáveis resgatem e eleve a sua capacidade de competição com as demais espécies, vale lembrar que esta prática deve ser aplicada de maneira alternada em cada piquete com o espaço de alguns anos (MELADO, 2003).

O pastejo diferido tem o privilégio de isentar o investimento em máquinas utilizadas na conservação de forragem. Entretanto, é interessante ressaltar que a eficiência deste método está absolutamente associada com a qualidade que a forragem presente na área diferida, terá no momento de ser consumida (MARASHIN, 1994; MIRANDA, 2007).

\section{Pastejo Limite}

Método que tem como finalidade manter os animais em pastagem de baixa qualidade ou até mesmo recebendo feno por um longo período. No entanto, concede que eles tenham acesso a um piquete de pastagem anual de maior qualidade durante certo período diário ou até mesmo a cada dois dias, para que assim diminua as perdas por pisoteio (MELADO, 2003).

\section{Pastejo rotacionado $\mathrm{x}$ contínuo}

O sistema de pastejo mais utilizado na região tocantinense é o pastejo contínuo, caracterizado pela permanência dos animais na mesma área durante todo o ano (VIEIRA, 1997). Há uma forte tendência para se encaixar a degradação de pastagem ao sistema de pastejo contínuo, considerando que se elas fossem empregadas no método de pastejo contínuo elas não se degradariam. Gerando uma comparação entre os sistemas, conclui-se que o rotacionado, na maioria das vezes é submetido a um grau de acompanhamento e controle bem mais exigente e aprimorado que o comum; já o contínuo normalmente é malconduzido (VIEIRA, 1997).

O ponto decisivo para o êxito de qualquer sistema de pastejo é a lotação animal, e esta é uma regra, bem monitorada no sistema de pastejo contínuo, já no pastejo contínuo, pouca atenção é dada a este fator (JÚNIOR, 2002). O sistema de pastejo rotacionado, exerce um fácil controle sobre os animais e pastagens e devido a este gerenciamento, os eventuais erros cometidos em um piquete podem ser facilmente corrigidos no próximo sem afetar todo o sistema, diferentemente do pastejo contínuo. Apesar de todas as qualidades do pastejo rotacionado é importante finalizar que, certas espécies forrageiras devido as suas características morfológicas e fisiológicas, devem ser obrigatoriamente manejadas em sistemas rotativos, o que gerar um maior benefício a este sistema (VIEIRA, 1997). 


\section{Espécies forrageiras para pastejo rotacionado}

Historicamente, pode-se ressaltar o gênero Brachiaria como gramínea de maior adaptação às condições endafoclimáticas do Cerrado, bioma pertencente ao Estado do Tocantins. Outro gênero com adaptação as mesmas condições é o Panicum que possui uma alta produtividade, elevada porcentagem de folhas, principalmente no período de estiagem, destacando-se também por apresentar menor estacionalidade de produção do que, por exemplo, a cv. Colonião (MÜLLER et al., 2002).

Dentre as vantagens encontradas nestes dois gêneros existe ainda a vantagem da menor estacionalidade, que em outras palavras significa "à redução de produção das pastagens em períodos em que há diminuição da disponibilidade de luz, a temperatura média é menor e a pluviosidade é drasticamente reduzida" (ASSUMPÇÃO et al., 2002).

Neste Bioma de Cerrado, a colocação de cultivares de plantas forrageiras em comparação com pastagens de espécies nativas, permite ganhos significantes à taxa de lotação animal, ponto marcante no sistema de pastejo rotacionado (JÚNIOR, 2002). Desta forma, em menos de três décadas o Cerrado tornouse a principal área de produção de carne bovina do Brasil, onde praticamente a totalidade desta produção é originária de sistemas extensivos, definidos por baixa produção animal e baixo retorno econômico (JÚNIOR, 2002).

Estes índices desfavoráveis divulgam o manejo inadequado do sistema solo - planta - animal o que predispõe a degradação de pastagens, sendo este o maior obstáculo para o estabelecimento de uma pecuária bovina sustentável, destacando de maneira nítida como solução a esta queda, a prática de pastejo rotacionado.

\section{Gêneros de plantas Forrageiras}

O Brasil é um país de clima tropical, onde existe um grande potencial de produção de carne e leite em pastagens. Dentre as várias gramíneas forrageiras destacam-se como os principais gêneros Panicum, Brachiaria e Stylosanthes, que ao serem bem manejadas podem se tornar o principal componente da dieta dos ruminantes (CORREIA et al., 2003).

\section{Gênero Brachiaria}

Tem um papel profundamente importante, pois viabiliza a pecuária de corte em solos ácidos e de baixa fertilidade dominante na região dos Cerrados, bioma tocantinense. Além de tudo facilitou o desenvolvimento das indústrias de sementes forrageiras posicionando o Brasil como maior exportador deste insumo para áreas tropicais (VALLE et al., 2000). As principais características das cultivares deste gênero serão apresentadas a seguir:

Brachiaria decumbens: é mais rústica das Brachiarias. Foi a primeira a ser introduzida no Brasil. Tem uma grande facilidade de adaptação em todos os tipos de solo e regiões tocantinenses. Possui uma alta 
produtividade em solos ácidos e de baixa fertilidade, principais características dos solos pertencentes ao Bioma do Cerrado. Possui uma boa palatabilidade e digestibilidade, pode ser manejada tanta em pastejo contínuo como em pastejo rotacionado (CORREIA et al., 2003). Esta espécie possui duas cultivares reconhecidas, porém somente uma é bastante conhecida e cultivada tanto no Brasil, quanto no Estado tocantinense.

Cultivar Basilisk: Também conhecida como "australiana" chega a apresentar de 0,3-1,0 cm de altura possuem um excelente potencial para produção de carne (CORREIA et al., 2003). Destaca-se também que foram diagnosticados casos de fotossensibilização em bezerros de 8 - 16 meses de idade, nas regiões dos Estados de São Paulo, Minas Gerais, Goiás e Mato Grosso, onde agente causador desta fotossensilidade hepátogena é o fungo Phitonmyces chartarum. Atualmente sabe-se que com manejo adequado desta forrageira e não a não ocorrência de muitas folhas mortas esta doença não ocorre ou é de baixa frequência, indica-se também que os bezerros não devem ser desmamados neste cultivar, pois o estresse da desmama agregado com a idade animal predispõe o aparecimento de fotossensibilização (SOUZA, 2006).

Para o pastejo rotacionado, a introdução dos animais deve ser com a gramínea entre $30-40 \mathrm{~cm}$ e a sua retirada em torno de 10-15 cm, devem ter um período de descanso de $30-35$ dias. Segundo VALLE et al. (2000), serão destacados abaixo alguns atributos positivos e negativos desta cultivar:

Atributos positivos: Facilidade em adaptação, tolerante em solos ácidos e pobres em fertilidade, excelente resposta a adubação, excelente produção de sementes, Facilidade na utilização em método de pasto vedado, ótimo desenvolvimento sob sombra.

Atributos negativos: Suscetibilidade á cigarrinha das pastagens, Hospedeira de fungos que provocam fotossensibilidade. Não se adapta a solos mal drenados. Difícil erradicação pelo acúmulo de sementes usual ao solo.

Brachiaria humidicola: Exibe uma vasta adaptação climática, tem uma ótima a atuação em solos ácidos, com elevada saturação de alumínio e com baixa fertilidade, com adaptação em solos com textura de franco á argilosos. Com velocidade intermediária de cobertura de solo, bem mais lenta que a espécie Brachiaria decumbens, possui uma boa proteção contra erosão depois de introduzida, bastante tolerante a estiagem, ao sombreamento, a queima e as pragas e doenças é também bastante tolerante á cigarrinha das pastagens (SOUZA, 2006). Porém, sua qualidade nutritiva é declarada como baixa, em termos principais de proteína, o que afeta seu consumo, o ganho de peso dos animais e a rapidez desta perda de qualidade é menor quando comparadas com as outras espécies deste gênero. Sua produção de forragem é considerada alta em solos argilosos e com boa precipitação, deve obter um período de descanso de 20 - 30 dias (SOUZA, 2006). No Brasil o écotipo mais comum desta espécie não recebeu denominação de cultivar (CORREIA et al., 2003). Segundo VALLE et al. (2000), serão destacados abaixo alguns atributos positivos e negativos desta espécie:

Atributos positivos: Possui tipo crescimento estolonífero, com uma capacidade de enraizamento nos nós, chega a proporcionar ao solo uma boa cobertura e um vasto domínio contra as plantas invasoras, possui facilidade de adaptação a solos de baixa fertilidade, mal drenado, bastante tolerante a cigarrinhas das pastagens. 
Atributos negativos: Baixo estabelecimento, baixa digestibilidade da massa seca, possui uma dormência das sementes por cerca de oito meses e é susceptível a ferrugem em áreas úmidas.

Brachiaria brizantha: Esta é uma das forrageiras mais plantadas no Brasil nos últimos anos, se destaca principalmente pelo seu elevado porte quando comparada com as outras espécies de Brachiaria. Esta é uma planta cespitosa, chega a produzir perfilhos que prevalecem eretos, apresenta pelos na porção apical dos entrenós. Pode-se encontrar cerca de três cultivares desta espécie sendo utilizadas comercialmente: Marandu, Xaraés e Piatã. Abaixo serão citadas as principais características dessas cultivares (SOUZA, 2006).

Cultivar Marandu: conhecida como Capim Marandu, é considerada como uma planta forrageira perene tropical com o maior volume de sementes comercializadas anualmente em todo país, sendo conhecida também como 'Brizantão' (DIAS FILHO, 2006). O manejo desta pastagem deve direcionar-se a uma ótima produção de forragem tanto em quantidade como também em qualidade, estas práticas de manejo mais adequados geram uma pastagem de qualidade a ser oferecida aos animais. Para obter este resultado descreve-se a entrada dos animais com a forragem a cerca de $50-60 \mathrm{~cm}$ de altura e com sua saída a cerca de $25-30 \mathrm{~cm}$. Tendo um período de descanso mínimo de 30 dias (DIAS-FILHO, 2006). Segundo VALLE et al. (2000), há alguns atributos positivos e negativos desta espécie:

Atributos positivos: Facilidade em estabelecer-se, possui resistência a cigarrinhas mais comuns em pastagens, ótima cobertura do solo com alto domínio as plantas invasoras, contêm um bom desenvolvimento sob sombra, elevada produção de raízes e de semente.

Atributos negativos: Difícil adaptação em solos mal drenados e com baixa fertilidade, rebrote lento, possui uma necessidade de reposição de nutrientes para ter uma persistência de longo prazo. Bastante suscetível à mancha foliar fúngica e a podridão das raízes.

Cultivar Xaraés: Esta é uma nova optação do gênero Brachiaria, tem uma elevada adaptação de solos ácidos e com baixa fertilidade do que a cultivar Marandu, possuindo uma alta resistência a cigarrinha das pastagens quando comparada com a cultivar Basilisk. É uma boa opção para forragem de engorda de bovinos na região do Cerrado, bioma tocantinense. Foi liberada comercialmente em 1994 (SOUZA, 2006). Segundo Valle et al., (2000), há atributos positivos e negativos desta cultivar:

Atributos positivos: Possui uma adaptação de alta facilidade, elevada produtividade principalmente de folhas, enraizamento dos nós o que proporciona uma boa cobertura do solo, rebrote rápido, com florescimento tardio o que prolonga a qualidade da forragem até o outono.

Atributos negativos: Baixa tolerância a cigarrinhas mais comuns, média adaptação em solos mal drenados e com baixa fertilidade e por conter florescimento tardio é susceptível a mela - das - sementes.

Cultivar Piatã: Esta é uma cultivar selecionada após 16 anos de estudo e avaliações da Embrapa, é recomendada para regiões com períodos de estiagem de até cinco meses. É citada como nova opção de diversificação de pastagens, por obter uma ótima qualidade quando comparada com a cv. Marandu e Xaraés, possuindo um elevado acúmulo de folhas e uma alta tolerância a solos mal drenados quando comparado com a cv. Marandu, e com uma maior adaptação ao pastejo diferido do que a cv. Xaraés (SOUZA, 2006). Conforme Valle et al., (2000), há alguns atributos positivos e negativos desta cultivar: 
Atributos positivos: Facilidade em se estabelecer, Maior produtividade de folhas principalmente durante a estiagem, florescimento precoce e bastante concentrado, elevada taxa de crescimento, resistência a cigarrinhas comuns.

Atributos negativos: Susceptível ao carvão das sementes (Ustilago operta), apresentação moderada à ferrugem (Puccinia levis, var. panici-sanguinalis).

\section{Gênero Panicum}

Este é um dos gêneros bastante amplo, e com uma vasta variabilidade genética e com diversas espécies e variedades. Porém será destacada uma espécie que provavelmente foi introduzida em nosso país por navios negreiros servindo como cama aos escravos, citada como Panicum Maximum. Esta é uma espécie de ótima adaptação edafoclimática, citando a cv. Colonião como a mais difundida e com a introdução mais antiga no Brasil, a demanda desta cultivar por um tempo desapareceu em virtude de cultivares mais produtivas (MÜLLER et al., 2002).

Porém a utilização de forragem deste gênero tem aumentado nos últimos anos, devido ao seu potencial de matéria seca por hectare e sua fácil adaptação. Desta maneira já foram lançadas outras diversas cultivares, porém como destaque para região tocantinense, serão citadas: Mombaça, Massai, Tanzânia e Tobiatã (MÜLLER et al., 2002).

\section{Panicum maximum}

As cultivares desta espécie que estão entre as forrageiras tropicais mais cultivadas do Brasil, e estão disponíveis de maneira essencial aos solos profundos, com boa drenagem e fertilidade, seus cultivos em solos que não satisfazem suas condições desejáveis e que não possuem um correto suprimento de nitrogênio têm demonstrado má formação, ou até mais comumente uma menor persistência sob o pastejo, com as consequentes perdas de capacidade produtiva e carência de ações corretivas para uma recuperação em curto prazo (CORREIA et al., 2003). As principais características das cultivares em utilização na região tocantinense serão apresentadas a seguir.

Cultivar Mombaça: Essa cultivar foi registrada no ano de 1993, ela apresenta uma elevada capacidade produtiva tanto de folhas como de matéria seca, possui uma ótima distribuição de produção, porém tem uma baixa produção de sementes quando comparada com o capim Tanzânia (MÜLLER et al., 2002). Esta é uma cultivar adequada para o pastejo rotacionado, bastante resistente à cigarrinha das pastagens, lembrando que seu primeiro pastejo deve ocorrer dentro do período de 90 - 120 dias após seu plantio, em comparação a acidez e a fertilidade são tão rigorosas quanto às demais cultivares do mesmo gênero, porém tem demonstrado elevada eficiência na utilização de fósforo do solo que as demais.

Atributos positivos: Excelente produção diante da adubação intensa, resistente à cigarrinha das pastagens e a lagarta das pastagens, ótima qualidade de forragem, ótima palatabilidade e digestibilidade, elevado percentual de folhas.

Atributos negativos: Baixa tolerância ao período de seca e a solos mal drenados, não tolera sombreamento, não se adapta a solos ácidos e com menor fertilidade. 
Cultivar Tanzânia: Esta é uma gramínea que pode atingir até $1,3 \mathrm{~m}$ de altura, suas folhas e bainha não apresentam pilosidade, nem cerosidade. É uma cultivar bastante exigente em fertilidade e principalmente em nutrientes de fósforo $(\mathrm{P})$ e potássio $(\mathrm{K})$ especialmente durante sua fase de implantação, devido a esta exigência recomenda-se, um controle de fertilidade através de análise (HERLING et al., 2000). Obteve ótimos resultados no sistema de pastejo rotacionado, com $1-5$ dias de pastejo e $25-30$ de descanso.

Atributos positivos: Facilidade em adaptação, rápida cobertura de solo, moderada resistência a cigarrinhas comuns, alto valor nutritivo e alimentício, melhor relação folha/haste, chega a apresentar uma moderada resistência à estiagem onde se recomenda um diferimento no final do período chuvoso para gerar um acúmulo de forragem de boa qualidade, durante o período de estiagem, ótima resposta sob pastejo rotacionado.

Atributos negativos: Não se adaptada á solos ácidos e de menor fertilidade, baixa tolerância a seca e a solos mal drenados, ultimamente tem manifestado uma baixa susceptibilidade a doenças foliares, como também ao carvão/cárie do sino que atinge as inflorescências o que pode comprometer seriamente a produção de sementes (HERLING et. Al.,2000).

Cultivar Massai: essa cultivar é um híbrido espontâneo entre Panicum maximum e Panicum infestum, é uma cultivar com uma ótima produção de forragem, bastante resistente ao fogo. Uma boa estratégia de aplicação deste capim é o pastejo rotacionado, as palavras chaves para sua definição são sustentabilidade e adaptabilidade, pois possui um desempenho bastante satisfatório quando comparado com outras cultivares, em relação à adaptação (MORAIS, 1995).

Atributos positivos: Ótima adaptabilidade, rapidez em relação a rebrota, boa cobertura de solo, bastante resistente à cigarrinha das pastagens.

Atributos negativos: Possui um baixo valor alimentício, médio requisito em fertilidade.

Cultivar Tobiatã: É uma cultivar de porte alto, foi registrada pelo Instituto Agronômico de Campinas, no ano de 1982, mesmo sendo uma cultivar de potencial produtivo elevado, a oferta desta semente tem diminuído nos últimos anos (MORAIS, 1995).

Atributos positivos: Facilidade em adaptação, alto valor nutritivo e alimentício, ótima resposta sob pastejo rotacionado.

Atributos negativos: Dificuldade na uniformização de pastejo, baixa produção de sementes, alta susceptibilidade a cigarrinha das pastagens.

\section{Importância do sistema rotacionado para criação de bovinos de corte no Tocantins}

Visto que a região tocantinense possui em sua maioria o predomínio do pastejo extensivo, é de grande importância considerar a aplicação do método rotacionado como alternativa tecnológica para uma melhor efetivação tanto da pastagem como do rendimento do próprio animal se tratando de bem-estar, resultado de carcaça, qualidade de carne e outros. Sistema de pastejo é entendido como a combinação integrada dos componentes: animal, planta, solo, clima, homem (MIRANDA, 2007 \& PEDREIRA et. al., 2005), sendo:

Clima: Apresentado por radiação solar, temperatura, umidade do ar, precipitações, estiagem;

Solo: São todas as suas características físicas, químicas e biológicas;

Planta: São as suas características principais de produtividade, de morfologia e composição química; 
Animal: Representado por suas principais características de espécie, raça, sexo, peso vivo, idade, condição nutricional;

Homem: Este ponto é apresentado pela forma de manejo dos outros quatro pontos presentes no sistema de pastejo.

Segundo Pedreira et al. (2005), o mais importante do que saber "o que acontece" é saber "por que acontece". Portanto é imprescindível a adoção de práticas tecnológicas de manejo de pastagens. Dentre várias vantagens encontradas (JÚNIOR et al., 2001) citam em uma pesquisa que o pastejo rotacionado possui um melhor aproveitamento de pasto, um consumo estável com baixo gasto energético do animal durante a procura de um alimento de maior qualidade. Suas pesquisas vieram demonstrar que este sistema chega a favorecer maiores ganhos por área. Porém um destaque prioritário é o exato dimensionamento do sistema para uma redução de custo estrutural para que se possa gerar uma relação de afinidade com a gramínea escolhida (NASCIMENTO JÚNIOR et al., 2001).

\section{Bem-estar animal}

Dentro do sistema de rotação encontrou-se a preocupação centrada em questões econômicas, envolvendo a viabilidade de utilização de insumos ou adotando sistemas sustentáveis de produção, onde se presume que apenas da produção de forragem decorre a produção do animal mantido a pasto (COSTA et al., 1997). Para os ruminantes que passam todo o seu ciclo mantido a pasto necessitam de vários recursos e estímulos além daqueles relacionados à oferta de alimento. Portanto é de extrema conveniência a análise do bem-estar tanto do animal quanto da forrageira, visando o maior rendimento de produção de ambas as partes.

O manejo em si se torna muito mais complexo e de certa forma obrigatório principalmente no tipo de criação de pastejo rotacionado, pois suas características acabam por criarem dificuldades para manutenção dos recursos necessários em se tratando do espaço em si e o próprio tempo, visto que pede um rígido controle do homem quanto a suas atividades para com os animais. Portando o tratador deve ter capaz de observar o animal a fim de identificar e quando o animal não estiver em estado condicional favorável, apresentando lesões, dores, patologias comportamentais, expectativa de vida reduzida, redução na habilidade de crescimento e reprodução, entre outras (BROOM et al., 1993, citado por COSTA et al., 1997).

Dentre os diversos recursos necessários para que os animais mantidos em pastagens tenham boas condições, alguns são imprescindíveis como, por exemplo, o espaço em si, permitindo que os animais não entrem em conflito com outros do mesmo grupo, e possam realizar suas atividades de forma tranquila, sem estresse por perto, além de abrigos, para que se protejam de situações climáticas (precipitações, veraneios, temperaturas altas), e os próprios alimentos, incluindo as forragens, suplementos, volumosos, concentrados e por último e não menos importante que tenham fácil acesso à água (REIS et al., 1997).

No entanto podem ocorrer riscos caso falte alguns dos fatores necessários, onde todos os aspectos são considerados desde que se analise o comportamento de cada animal, onde se inclui espécie, sexo, raça, idade, ciclo entre outros. Para exemplificar têm-se as seguintes situações: uso do espaço e suas 
consequências futuras para com as relações sociais, restrições no acesso à água, restrições no acesso à sombra e a rejeição da forragem contaminada pelas fezes dos próprios animais (MARTIN, 2005).

Sobre as restrições no acesso à sombra Reichert (2007) em seus testes, concluiu que o sombreamento é benéfico ao animal, pois acaba por reduzir o aquecimento corporal além de facilitar a termorregulação dele. "Fatores sociais envolvendo hierarquia e territorialismo", também influenciam na preferência por sombra entre os bovinos.

Quanto à rejeição da forragem contaminada pelas fezes dos próprios animais é de fato uma questão preocupante para os pesquisadores, pois grande parte da forragem pode ser perdida, pois o animal reluta em comer a forragem próxima de suas fezes, e se o faz, tem seu rendimento e bem-estar afetado, causando prejuízos. Resultados de pesquisas realizadas em sistemas de pastejo rotacionado, mostraram que houve uma grande rejeição de forragem devido à contaminação por fezes atingindo uma perda de 38 a 47\%, e a perca de aproximadamente de $73 \%$ de forragem que estava próxima às placas (REICHERT, 2007).

\section{CONSIDERAÇÕES FINAIS}

Dentre todos os aspectos discutidos e fundamentados sobre o pastejo rotacionado, buscou-se analisar sua vantagem como alternativa para um melhor manejo, e maior rendimento da produção, principalmente quando o objetivo final do produtor é a pecuária de corte, onde se busca alcançar uma carne de qualidade que satisfaça o desejo do consumidor, ao mesmo tempo em que proporcione lucro ao produtor e criador.

A escolha da forragem a ser implantada deve ser um fator analisado inicialmente pelo produtor, onde precisam ser observados, por exemplo, forrageiras que obtenham um rápido crescimento acompanhando o seu tempo de descanso, quando neste caso os animais forem colocados em outro piquete. Valor nutricional oferecido pela forragem, adaptabilidade, palatabilidade, tempo de crescimento e ciclo, para que futuramente não sejam recusados e desperdiçados pelo próprio animal, causando assim um prejuízo ao produtor.

Pelos resultados obtidos dos vários experimentos, os pesquisadores comprovaram que dentre todos os aspectos o mais analisado é o bem-estar animal, não se pode investir em um projeto de alto valor, por exemplo, se este fator não for considerado isoladamente. Sabe-se que a o rendimento da produção só terá efeito se o animal for bem tratado, e dessa forma será recíproco ao criador, pois o animal se encontrará em condições favoráveis para se desenvolver. Caso contrário, o rendimento será desfavorável para ambas as partes.

Nos últimos anos pesquisas comprovam o crescimento de áreas de pastagens e índices de abates para o Estado do Tocantins mostrando o destaque do Estado se comparado a outros com níveis similares em produtividade. Visto que a pecuária de corte possui um ciclo longo de produção percorrendo de $5-7$ anos, é imprescindível que o criador esteja apto a acompanhar de forma eficiente as fases de cria - recria e engorda do animal, que se examine e avalie a forrageira incluindo período de ocupação, lotação empregada, 
dimensionamento de piquetes, correção do solo, adubações e/ou o uso da irrigação se possível ou necessário, para que a mesma receba o animal em boas condições.

Onde de fato o animal realize a coleta da forragem no ponto ideal de interseção (entre o melhor valor nutricional e a maior produção quando o lote adentra a um determinado piquete). Nessa perspectiva, a utilização do pastejo rotacionado torna-se necessário, pois é neste sistema que se harmonizará aspectos correlacionados como o solo - planta - animal e o próprio ambiente.

\section{REFERÊNCIAS}

ASSUMPÇÃO, A. D. J. J.. Estratégias para Enfrentar a Estacionalidade de Produção das Plantas Forrageiras sem Conservar Forragens. Piracicaba: 2002.

BARRETO, I. L.; PEIXOTO, A. M.; MOURA, C. I.; FARIA, P. V. G.. Pastejo contínuo. Piracicaba: Pastagens, 1994.

BROOM, D. M.; JOHNSON, K. G.. Stress and animal welfare. London: Chapman and Hall, 1993.

CEZAR, I. M.; QUEIROZ, H. P.; THIAGO, L. R. L. S.. Sistemas de produção de gado de corte no Brasil: uma descrição com ênfase no regime alimentar e no abate. Embrapa Gado de Corte, Campo Grande, 2005.

CORREIA, A. L.; SANTOS, M. P.. Manejo e utilização de plantas forrageiras dos gêneros Panicum. Embrapa Pecuária Sudeste, São Carlos, 2003.

COSTA, L. N.. Manejo de Pastagens Tropicais. Macapá: 2007.

COSTA, M. J. R. P.; CROMBERG, V. U.. Alguns aspectos a serem considerados para melhorar o Bem-Estar de animais em sistema de pastejo rotacionado. In: Fundamentos do pastejo rotacionado. Piracicaba: FEALQ, 1997.

DIAS-FILHO, M. B.. Respostas morfológicas de Brachiaria spp. ao alagamento do solo e a síndrome da morte do capim- marandu. In: Morte de pastos de braquiárias. Embrapa Gado de Corte, Campo Grande, 2006.

HERLING, V. R.; BRAGA, G. J.; LUIZ, P. H. C.. Tobiatã, Tanzânia e Mombaça. SIMPÓsIO SOBRE MANEJO DE PASTAGENS. Anais. Piracicaba: FEALQ, 2000.

JÚNIOR, D. N.; NETO, F. A. G.. Complexidade e Estabilidade de pastejo. Viçosa: Universidade Federal de Viçosa, 2001.

JÚNIOR, G. B. M.. Sistema de produção animal em pastejo: Um enfoque de negócio. Embrapa Cerrados, Planaltina, 2002.
MARASHIN, G. E.. Sistema de pastejo 1. In: Pastagens e Fundamentos da exploração racional. Piracicaba: FEALQ, 1994.

MARTIN, C. I.; PIRES, Q. H.. Sistemas de Produção de Gado de Corte no Brasil: Uma Descrição com Ênfase no Regime Alimentar e no Abate. Campo Grande: Embrapa Gado de Corte, 2005

MELADO, J.. Pastoreio Racional de Voisin:

Fundamentos, aplicações e projetos. Viçosa: Aprenda Fácil, 2003.

MENDES, A. P.; MOURA, J. C.; PEDROSO, V. F.. Produção de Bovinos a Pasto. In: SIMPÓSIO SOBRE MANEJO DE PASTAGEM, 13. Anais. Piracicaba: FEALQ, 1999.

MIRANDA, A. V.. Sistema de pastejo. Brasília: Universidade Castelo Branco, 2007.

MORAIS, Y. J. B.. Forrageiras: Conceitos, formação e manejo. Guaíba Agropecuária, 1995.

MÜLLER, S. M., FANCELLI, D.; DOURADO, L. A.; GARCIA, D. N. A.; LÓPEZ, O. R. F.. Produtividade do Panicum maximum cV. Mombaça irrigado, sob pastejo rotacionado. Scientia Agrícola, Piracicaba, v.59, n.3, 2002.

NOGUEIRA, SIMÕES C. A.. Gado de Corte. Embrapa Informação Tecnológica, Brasília, v.2, 2011.

PEDREIRA, C. G. S.; SILVA, S. C.; BRAGA, G. J.; NETO, J. M. S.; SBRISSIA, A. F.. Sistemas de pastejo na exploração pecuária brasileira. Piracicaba: ESALQ, 2005.

REICHERT, J. M.. Compactação do Solo em Sistemas Agropecuários e Florestais: Identificação, Efeitos, Limites, Críticos e Mitigação. Campinas: Cia. Solo, 2007.

REIS, R. A.; RODRIGUES, L. R. A.. Fundamentos do pastejo rotacionado. SIMPÓSIO SOBRE MANEJO DE PASTAGEM, 14. Anais. Piracicaba: FEALQ, 1997. 
SILVA, S. C.. Condições edafoclimáticas para a produção de panicum. SIMPÓSIO SOBRE MANEJO DA PASTAGEM. Anais. Piracicaba: FEALQ, 1995.

SOUZA, A.. Fatores que afetam o consumo de gramíneas forrageiras e o desempenho animal. Araras: BeefPoint, 2006.

TAYAROL, M. L. C.. Bovinos, Volumosos

Suplementares. São Paulo: Nobel, 1997.

VALENTIM, J. F.; AMARAL, E. F.; LANI, J. L.. Definição das zonas de risco de morte de pastagens de
Brachiaria brizantha cv. Marandu no Estado do Acre. REUNIÃO BRASILEIRA DE MANEJO E CONSERVAÇÃO DO SOLO E DA ÁGUA. Anais. Cuiabá: SBCS, 2002.

VALLE, C. B.; EUCLIDES, V. P. B.; MACEDO, M. C. M.. Características das plantas forrageiras do gênero Brachiaria. SIMPÓSIO SOBRE MANEJO DE PASTAGEM, 17. Anais. Piracicaba: FEALQ, 2000.

VIEIRA, M. J.. Uso intensivo de pastagens. Embrapa Gado de Corte, Campo Grande, 1997. 